\title{
An Environmentally Benign Supercapacitor Using A Water-dissolvable Ionic Gel
}

Shunsuke Yamada*

Room 113, Building No. A15, Area A01, 6-6-01 Aoba, Aramakiaza, Aobaku, Sendaishi, Miyagi, 980-8579, Japan

Corresponding Author

Shunsuke Yamada

Room 113, Building No. A15, Area A016-6-01 Aoba, Aramakiaza, Aobaku, Sendaishi, Miyagi, 980-8579, Japan.

orcid.org/0000-0002-9084-2070;

e-mail: santa@tohoku.ac.jp 
ABSTRACT. An environmentally benign supercapacitor is developed incorporating an ionic liquid, carbon powder, a cellulose separator and a Molybdenum electrode. The ionic liquid is dispersed into a water-dissolvable polymer, poly(vinyl alcohol), to produce solid electrolyte, socalled an ionic gel. A carbon composite mixed with the ionic liquid maintains a gel form. The ionic gel and the carbon composite enable an all-solid-state supercapacitor which can be charged at the voltage of $1.5 \mathrm{~V}$. The supercapacitor shows areal and volumetric capacitance of $65 \mathrm{mF} / \mathrm{cm}^{2}$ and $2.2 \mathrm{~F} / \mathrm{cm}^{3}$. A cycle test reveals that capacitance retention and coulombic efficiency are $77 \%$ and $90 \%$, respectively. As for dissolution test, the ionic gel and carbon composite dissolves into phosphate buffer solution in 18 days, and the Mo electrode is able to fully dissolve in 500 588 days. Potential applications of the environmentally benign supercapacitor include smart agriculture by monitoring of soil, disaster prevention by the wireless sensor network without need for retrieval of devices after use. 


\section{Introduction}

As the development of wireless sensor networks, use of the electronic devices will expand from inside to outside, and the electronic waste (e-waste) will not be retrieved from the environment to remain after use. The abandoned e-waste could trigger adverse effect on nature. Resins, for example, decomposes to become microplastic which accumulates on organs of living things in sea; electrolytes of batteries possess toxicity, and may result in pollution of the environment by leakage from packages. It is, therefore, essential to reduce the e-waste and protect the environment from the pollution of harmful substances leaked from e-waste. The retrieval of e-waste is challenging because wireless sensor modules are expected to be installed in places where humans are unable to access easily. Researchers, thus, have developed biodegradable electronic devices including, transistors, sensors, and batteries which decompose into environmentally benign materials after prescribed time ${ }^{1-6}$; such a new class of electronic devices is so-called transient electronics ${ }^{7-9}$. As for the transient batteries, a supercapacitor represents high power density and cycle stability, and hence is a promising candidate for a battery of wireless sensor modules. A previous work reported the supercapacitor employing biodegradable materials of metals (Mo, W, and Fe), a polymer (poly(lactic-co-glycolic acid)), and a gel electrolyte (agarose) ${ }^{1}$. Despite the fact that the supercapacitor shows negligible change of capacitance after 10000 cycles, flexibility, and biodegradability, the evaporation of water is inevitable for such an aqueous electrolyte, which may provide a negative influence on long term operation. Furthermore, a potential window of the aqueous electrolyte is around $0.8 \mathrm{~V}$ due to electrolysis of the water, which needs the multiple supercapacitors connected in series to operate commercial electronic devices operated at $3.0 \mathrm{~V}$.

Here, we report a biodegradable supercapacitor (BDSC) with an ionic gel (IG) made of the ionic liquid, $[\mathrm{MTEOA}]\left[\mathrm{MeOSO}_{3}\right]$ and the poly(vinyl alcohol) (PVA), to address the issues as 
shown in Figure 1h. The ionic liquid that consists of a pair of ions shows extremely low vapor pressure, large potential window, and high ionic conductivity. Furthermore, the ionic liquid is able to be dispersed into the PVA, to form an ionic gel ${ }^{10}$, which is suitable for applications of battery and flexible/stretchable electronics ${ }^{10-12}$. We adapt molybdenum (Mo), carbon, cellulose, and ionic gel as a current collector, an electrode, a separator, and an electrolyte, respectively, to develop the supercapacitor. The carbon is environmentally benign, and the Mo and the ionic gel possess biodegradability, which enables us to develop the harmless supercapacitor to the environment. The cyclic voltammetry indicates that the developed BDSC shows the electrochemical stability with a voltage ranging from 0 to $1.5 \mathrm{~V}$, which value is almost twice as large as the supercapacitor with aqueous electrolytes. The BDSC exhibits areal and volumetric capacitance of $65 \mathrm{mF} / \mathrm{cm}^{2}$ and 2.2 $\mathrm{F} / \mathrm{cm}^{3}$, respectively with a discharge current density of $0.2 \mathrm{~mA} / \mathrm{cm}^{2}$. According to the Nyquist plot of the BDSC, the BDSC shows capacitive behavior in low frequency regime. As of equivalent series resistance (ESR) of the device, the resistance of $59 \Omega$ is obtained by fitting with an equivalent circuit models. The two BDSCs connected in series increases a voltage limit of $3 \mathrm{~V}$, and were able to illuminate LEDs for 150 seconds. As for dissolution of the BDSC, the carbon composite and ionic gel dissolved 18 days after soaking into PBS solution heated at $100^{\circ} \mathrm{C}$. The Mo electrode is able to completely dissolve in 500 588 days according to previous studies ${ }^{3,13}$. The environmentally benign supercapacitor allows operation of electronics devices in outsides without pollution of the environment, and eliminates need for retrieval after use. The future applications of the environmentally benign supercapacitor include smart agriculture by monitoring of soil, disaster prevention by the wireless sensor network.

\section{Results and Discussion}




\subsection{Device fabrication.}

Figure 1a displays a schematic illustration of the BDSC which consist of the Mo electrode, composite of carbon black and the ionic liquid (CIL), cellulose separator, and IG electrolyte. The CIL was coated on a Mo electrode by a doctor blade method using a $50 \mu$ m-thick mold to obtain an active electrode with the area of $10 \mathrm{~mm} \times 10 \mathrm{~mm}$. The IG precursor was coated on the Mo electrode and the CIL by dip-coating, followed by dried in the ambient air for 1 day. The IG covered the CIL on the Mo electrode as shown in Figure 1d. A pair of Mo electrodes and the cellulose separator were laminated to yield the Mo-separator-Mo configuration using the IG precursor as glue. Intersection of the BDSC by a scanning electron microscope (SEM) appears in Figure 1e, which indicates that the PVA in the IG enables tightly adheres the electrodes, CIL, and separator.

\subsection{Raman spectroscopy and XRD.}

Previous studies reports that the intercalation of the ionic liquids into emerging materials including, graphene $\mathrm{e}^{14}, \mathrm{CNT}^{15}$, and MXenes ${ }^{16}$ enhances electrical and mechanical properties. The CNT forms a bundle due to the strong Van der Waals force associated with the one-dimensional structure, and therefore solvents are unable to disperse the bundle. Nonetheless, the cation in the ionic liquid shows cation- $\pi$ interaction with the surface of the CNT, which results in numerous weak physical crosslinks to disperse the CNT into the ionic liquid. The mixture of ionic liquid and carbon nanotube, so called "bucky gel"17-20, shows high electrical conductivity and mechanical robustness. The MXenes and graphene are an emerging two-dimensional (2D) material due to the atomically thin and flat structure and intrinsic flexibility. The intercalation of the ionic liquid into those nanosheets realizes large ion-accessible surface area and fast ionic transportation, which 
results in the large volumetric capacitance, high areal energy density, and volumetric energy density ${ }^{15,16}$. A study of Raman and X-ray Diffraction (XRD) spectroscopy were performed on the CIL in this work to figure out the nanostructure by the cation- $\pi$ interaction between the carbon black and ionic liquid.

As for the XRD measurement, the CIL was coated on a glass substrate to form a $50 \mu \mathrm{m}$ thick layer as shown in Figure 2a. As a reference sample for the measurement, we placed carbon powder in the mold on the glass substrate, and gently removed excess powder by the doctor blade method to form the $50 \mu$ m-thick layer. Figure $\mathbf{2 b}$ shows XRD patterns of the CIL and carbon powder. The carbon powder shows a broad peak at $2 \theta=26^{\circ}$, which is attributed to the graphitic structure $(002)$ in the carbon powder ${ }^{21,22}$. The composite, on the other hand, shows a sharp peak $2 \theta=28^{\circ}$ with the $d$ spacing of $3.25 \AA$. We assume that the sharp peak $2 \theta=28^{\circ}$ is associated with the molecular ordering by cation $-\pi$ interaction between the carbon black and the ionic liquid. The intercalation of the ions is supposed to shift the $2 \theta$ of the carbon black to decrease by increase of the $d$ spacing; the $2 \theta$ of the composite is, however, higher than that of the carbon black. According to previous works, the ions are intercalated into every several layers of the graphitic structure, which number of the layer is referred as the intercalation stage $\mathrm{e}^{23}$. The peak more than $26^{\circ}$ in the XRD profile corresponds to the intercalation stage which is higher than three. The intercalation of the ions of the IL allows the increase of the accessible surface area of the carbon black to boost the capacitance.

Figure 2c shows the Raman shift of the carbon powder and the CIL. The graphs represent two peaks of D-band $\left(1350 \mathrm{~cm}^{-1}\right)$ and G-band $\left(1580 \mathrm{~cm}^{-1}\right)$ associated with the disorder of the graphene structure and the graphene structure in the carbon powder, respectively ${ }^{24,25}$. We define the ratio of the intensity of D-band $I_{\mathrm{D}}$ and G-band $I_{\mathrm{G}}$ as 


$$
I_{\mathrm{R}}=\frac{I_{\mathrm{D}}}{I_{\mathrm{G}}}
$$

The $I_{\mathrm{R}}$ of the carbon and carbon paste are of 1.04 and 1.08, respectively. The $I_{\mathrm{R}}$ shows no change with and without ionic liquid, and therefore the ionic liquid does not chemically modify the carbon powders. This result agrees with the previous work of bucky gel ${ }^{17}$.

\subsection{Cyclic voltammetry.}

A study of cyclic voltammetry (CV) was performed to investigate the electrochemical characteristics of the BDSC. Unless otherwise noted, the experiments were performed in a chamber filled with 1-atm nitrogen gas. Figure 3a shows the CV curves with scan rates varying from $5 \mathrm{mV} / \mathrm{s}$ to $300 \mathrm{mV} / \mathrm{s}$. The $\mathrm{CV}$ curves remain quasi-rectangular shapes up to $300 \mathrm{mV} / \mathrm{s}$. The $\mathrm{CV}$ curves with aqueous electrolyte shows peak at $0.8 \mathrm{~V}$ due to electrolysis of water. The BDSC with the ionic liquid, [MTEOA] $\left[\mathrm{MeOSO}_{3}\right]$, shows no peak within $1.5 \mathrm{~V}$. According to this result, the developed supercapacitor is able to exhibit 1.8 and 3.5 times as large charge and energy capacity as those of supercapacitor with aqueous electrolyte with the same capacitance, respectively.

\subsection{Galvanostatic charge-discharge.}

We performed a galvanostatic charge-discharge (GCD) to investigate capacitance of the supercapacitor. As shown in Figure 3b, a line in a GCD profile is sloping and almost symmetric triangular shape with charge and discharge current density of $0.20 \mathrm{~mA} / \mathrm{cm}^{2}$, which reveals that the developed supercapacitor shows ideal capacitive behavior. It should be noted that the current density was calculated by dividing the applied current by the area of carbon paste. The areal capacitance $C_{\text {areal }}$ and volumetric capacitance $C_{\text {vol }}$ are written as 


$$
\begin{gathered}
C_{\text {areal }}=\frac{i \times t}{S\left(V_{\mathrm{e}}-V_{\mathrm{d}}\right)}, \\
C_{\mathrm{vol}}=\frac{i \times t}{T S\left(V_{\mathrm{e}}-V_{\mathrm{d}}\right)},
\end{gathered}
$$

where $i$ is the discharge current, $t$ is the time of discharge, $T$ is the thickness of the supercapacitor, $S$ is the area of carbon paste, $V_{\mathrm{e}}$ is voltage after charging, and $V_{\mathrm{d}}$ is the voltage drop during the discharge ${ }^{16}$. The $C_{\text {areal }}$ and $C_{\mathrm{vol}}$ with the discharge current density of $0.20 \mathrm{~mA} / \mathrm{cm}^{2}$ is of $65 \mathrm{mF} / \mathrm{cm}^{2}$ and $2.2 \mathrm{~F} / \mathrm{cm}^{3}$, respectively. As the increase of the discharge current density up to $2.0 \mathrm{~mA} / \mathrm{cm}^{2}$, the $C_{\text {areal }}$ and $C_{\text {vol }}$ slightly decrease to $54 \mathrm{mF} / \mathrm{cm}^{2}$ and $1.8 \mathrm{~F} / \mathrm{cm}^{3}$, respectively, as shown in Figure 3c and Figure 3d.

Figure 3e summarizes changes of the $C_{\text {areal }}$ and coulomb efficiency during a cycle test with the discharge current density of $1.0 \mathrm{~mA} / \mathrm{cm}^{2}$. The capacitance decreased by $33 \%$ after 1400 cycles, then recovered to be $77 \%$ after 4,800 cycles. The recovery of the capacitance results from the intercalation of the ions into the carbon and the pores. The coulombic efficiency remained more than $90 \%$ during the cycle test. The capacitance retention and coulomb efficiency after 10000 cycles are comparable to conventional ionic liquids, e.g., 1-Ethyl-3-methylimidazolium bis(trifluoromethylsulfonyl) imide $\quad([\mathrm{EMIM}][\mathrm{TFSI}])^{26}, \quad$ 1-ethyl-3-methylimidazolium tetrafluoroborate $\left([\mathrm{EMIM}]\left[\mathrm{BF}_{4}\right]\right)^{27-29}$, and 1-ethyl-3-methylimidazolium tris(pentafluoroethyl) trifluorophosphate $([\mathrm{EMIM}][\mathrm{FAP}])^{30}$.

Figure 3f and 3g show areal and volumetric Ragone plots, respectively, to compare the energy and power densities with a commercial supercapacitor (Panasonic, EECRF0H104N) and Al electrolytic capacitor (nichicon, UVR1E471MPD), where the areal energy $\boldsymbol{E}_{\text {areal }}$ and power 
density $\boldsymbol{P}_{\text {areal }}$, volumetric energy $\boldsymbol{E}_{\mathrm{vol}}$ and power density $\boldsymbol{P}_{\mathrm{vol}}$ were calculated by following equations ${ }^{16}$ :

$$
\begin{gathered}
E_{\text {areal }}=\frac{1}{2} \times C_{\text {areal }} \times \frac{\left(V_{\mathrm{e}}-V_{\mathrm{d}}\right)^{2}}{3600}, \\
P_{\text {areal }}=\frac{E_{\text {areal }}}{t} \times 3600, \\
E_{\mathrm{vol}}=\frac{1}{2} \times C_{\mathrm{vol}} \times \frac{\left(V_{\mathrm{e}}-V_{\mathrm{d}}\right)^{2}}{3600}, \\
P_{\mathrm{vol}}=\frac{E_{\mathrm{vol}}}{t} \times 3600 .
\end{gathered}
$$

The areal energy and power densities of the developed supercapacitor are $19 \mu \mathrm{Wh} / \mathrm{cm}^{2}$ and 1.1 $\mathrm{mW} / \mathrm{cm}^{2}$, respectively, whereas the commercial supercapacitor shows $338 \mu \mathrm{Wh} / \mathrm{cm}^{2}$ and 9.0 $\mathrm{mW} / \mathrm{cm}^{2}$; the Al electrolytic capacitor shows $3.3 \mu \mathrm{Wh} / \mathrm{cm}^{2}$ and $19 \mathrm{~mW} / \mathrm{cm}^{2}$. Those values of the BDSC are smaller than those of $\mathrm{Al}$ electrolytic capacitor and commercial supercapacitor due to the thin configuration. The BDSC shows remarkably high volumetric energy and power densities of $632 \mu \mathrm{Wh} / \mathrm{cm}^{3}$ and $38 \mathrm{~mW} / \mathrm{cm}^{3}$, respectively. The volumetric energy density of BDSC is two orders of magnitude higher than that of the Al electrolytic capacitor $\left(2.6 \mu \mathrm{Wh} / \mathrm{cm}^{3}\right)$, and 2.7 times higher than that of the commercial supercapacitor $\left(238 \mu \mathrm{Wh} / \mathrm{cm}^{3}\right)$. The volumetric power density of BDSC is 2.7 times and 6.0 times higher than those of the $\mathrm{Al}$ electrolytic capacitor $\left(14 \mathrm{~mW} / \mathrm{cm}^{3}\right)$ and commercial supercapacitor $\left(6.3 \mathrm{~mW} / \mathrm{cm}^{3}\right)$, respectively. 
Figure 3h shows change of the Nyquist plot of the BDSC with a frequency ranging from $10 \mathrm{mHz}$ to $1 \mathrm{MHz}$ after $1^{\text {st }}$ and $10000^{\text {th }}$ cycles, where dots and lines show experimental and fitting results using an equivalent circuit model ${ }^{31-33}$ as displayed in Figure 3i, respectively. The equivalent circuit model is composed of equivalent series resistance $\boldsymbol{R}_{\mathrm{s}}$, charge transfer resistance $\boldsymbol{R}_{\mathrm{ct}}$, leakage resistance $\boldsymbol{R}_{\text {leak }}$, Warburg element $\boldsymbol{W}$, constant phase elements $\boldsymbol{Q}_{1}, \boldsymbol{Q}_{2}$. The $\boldsymbol{R}_{\mathrm{s}}$ after the 1 st cycle is of $36 \Omega$; the low $\boldsymbol{R}_{\mathrm{s}}$ is attributed to a conformal contact between the current collector and the electrode, which reduces the electron-transfer resistance ${ }^{34}$. The $\boldsymbol{R}_{\mathrm{s}}$ increases after the $10000^{\text {th }}$ cycle to be $82 \Omega$, and the increase of the $\boldsymbol{R}_{\mathrm{s}}$ could result from the oxidization of the electrode and/or corrosion of the electrode ${ }^{35}$. The Mo electrode is subject to be oxidized by the aqueous electrolyte, which grows $\mathrm{MoO}_{3}$ on the electrode to increases the $\boldsymbol{R}_{\mathrm{s}}{ }^{1}$. The IL was heated to expel the moisture inside, however a few weight percent of the water could have remained in the ionic liquid ${ }^{16}$. We assume that a small amount of water in the ionic liquid oxidized the Mo electrode by applied current. As shown in Figure 2c, the ions are intercalated into the graphitic structure, and the high accessible surface area results in the fast ion transport of the BGiD; the $\boldsymbol{R}_{\mathrm{ct}}$ was, therefore, as low as $21 \Omega$ after the $1^{\text {st }}$ cycle. The ionic liquid provides physical bonding with the carbon to render the CIL soft to easily deform by mechanical pressure. The charge-discharge cycle causes mechanical expansion of the $\mathrm{CIL}^{36-38}$, and hence degradation of the contact between the CIL and IG occurs to increase the $\boldsymbol{R}_{\mathrm{ct}}$ of $70 \Omega$. The constant phase elements, $\boldsymbol{Q}_{1}$ and $\boldsymbol{Q}_{2}$, corresponding to double layer capacitance and pseudo-capacitance, respectively, show negligibly small change before after the cycles.

\section{Multiple supercapacitor}


The capacitance of the BDSC could be insufficient for certain applications, and increase of the total capacitance by the parallelly connected BDSCs are essential. Figure 4 a shows the CV curves of supercapacitor of one cell and two cells in parallel with the scan rate of $10 \mathrm{mV} / \mathrm{s}$. The current density of two cells in parallel is almost twice as large as that of supercapacitor of one cell due to the increase of the total capacitance. The charge and discharge time of two cells in parallel is almost doubled, compared with that of one cell, according to the GCD profiles as displayed in Figure $4 \mathbf{b}$. We calculated the capacitance using the following equation ${ }^{1,39}$,

$$
C_{\text {areal }}=\frac{i \times t}{S\left(V_{\mathrm{e}}-V_{\mathrm{d}}\right)} .
$$

The capacitance of one cell and two cells in parallel are of $63 \mathrm{mF}$ and $111 \mathrm{mF}$, respectively. Compared with the capacitance of one cell, the capacitance of two cells is doubled with the current ranging from $0.2 \mathrm{~mA}$ to $2 \mathrm{~mA}$ as shown in Figure $\mathbf{4 c}$.

The study of the $\mathrm{CV}$ reveals that the maximum voltage which we are able to apply on the BDSC is of $1.5 \mathrm{~V}$, however the value is not sufficiently high to operate electronic devices. To expand the voltage limit, we connected two BDSC in series, and performed the CV and GCD to investigate the characteristics. Figure $4 \mathbf{d}$ shows the CV curves of one cell and two cells in series with the scan rate of $10 \mathrm{mV} / \mathrm{s}$. Although the current density of two cells in series shows almost 0.5 times smaller than that of one cell because of the reduction of total capacitance, the CV curve of two cells in series shows no peak with the voltage range from $0 \mathrm{~V}$ to $3 \mathrm{~V}$. This result indicates that the voltage limit increased from $1.5 \mathrm{~V}$ to $3.0 \mathrm{~V}$, which enables operation of commercial electronic devices including light-emitting diode (LED), MPU, and sensors. The GCD profile of two cells in series is sloping and the quasi-triangular shape with the discharge current density of $0.5 \mathrm{~mA} / \mathrm{cm}^{2}$ and the voltage ranging from $0 \mathrm{~V}$ to $3 \mathrm{~V}$ as shown in Figure 4e. The capacitance of two cells in series is of $29 \mathrm{mF}$, which value is almost half of that of one cell $(63 \mathrm{mF})$, which agrees with the 
result of the CV. As shown in Figure 4f, the capacitance of one cell remains large as the discharge current density increases, and so does the capacitance of two cells in series.

Figure $4 \mathrm{~g}$ and $\mathbf{4 h}$ shows electrical circuit and a photograph for the LED illumination as a practical application of the BDSC. The BDSCs with two cells in series were charged at $3.0 \mathrm{~V}$, and able to illuminate the three red LEDs for 150 seconds as shown in Figure 4i. This result suggests that the BDSC is able to operate the commercially available electronic devices, and serve as the power source for the biodegradable wireless sensor modules. The applications of such modules include the environmental sensing for forecast of disasters, e.g., flood, mudflow, and wildfire. The environmentally benign module has an opportunity to monitor soil, rivers, and seas without environmental pollution, which allows the expansion of the application for agriculture, fishery, and animal husbandry.

\subsection{Dissolution into PBS.}

We immersed the BDSC into $0.01 \mathrm{M}$ phosphate buffer solution (PBS) to investigate transient behavior during dissolution of the BDSC. The sample in PBS solution was kept in an oven at $100^{\circ} \mathrm{C}$, which accelerated the dissolution. We refreshed the PBS solution every two days. In the

first day, the Mo foil showed glossy gray color without significant change. The BDSC, then, delaminated into the cellulose separator, CIL, and Mo electrodes in 1 day. The dissolution of the IG, gradually, broke down the CIL into small pieces as shown in the photograph in 9 days. The Mo electrode changed the color from glossy gray to dark gray in 18 days. It should be noted that the Mo foil did not dissolve within 18 days. The dissolution rate of the Mo film is $0.017 \mu \mathrm{m} / \mathrm{d} \sim$ $0.02 \mu \mathrm{m} / \mathrm{d}^{3,13}$ according to the previous studies, and therefore the $10 \mu \mathrm{m}$-thick Mo film in this work completely dissolve in $500 \sim 588$ days. 


\section{Conclusion}

An environmentally benign supercapacitor has been developed using a water-dissolvable ionic gel incorporating an ionic liquid and the PVA. The supercapacitor is charged at the voltage of $1.5 \mathrm{~V}$, and possesses the areal and volumetric capacitance of $65 \mathrm{mF} / \mathrm{cm}^{2}$ and $2.2 \mathrm{~F} / \mathrm{cm}^{3}$. A study on the cycle test reveals that capacitance retention and coulombic efficiency are $77 \%$ and $90 \%$, respectively. The supercapacitor decomposes by a contact with water. The ionic gel and carbon composite dissolve into phosphate buffer solution in 18 days, and the Mo electrode could fully dissolve in $500 \sim 588$ days. The environmentally benign supercapacitor will deserve to be the power source of modules which are installed in outdoors including smart agriculture by monitoring of soil, disaster prevention.

\section{Experimental Section}

Fabrication of BDSC. The process started with fabrication of the CIL. We thoroughly mixed carbon powder (TOYO TANSO, CNovel MJ(4)010) with the ionic liquid (Sigma-Aldrich, catalog ID 91198) with weight ratio of carbon: IL $=2: 8$ to obtain the composite. The CIL was coated on a $10 \mu \mathrm{m}$-thick Mo sheet (Nilaco, MO-293171) to obtain the electrode with the area of $10 \mathrm{~mm} \times 10$ $\mathrm{mm}$ by the doctor blade method using the $50 \mu \mathrm{m}$-thick mold. The PVA (Sigma-Aldrich, molecular weight $89,000-98,000,99^{+} \%$ hydrolyzed, catalog ID 341584 ) and the IL were dissolved into DIW using an oven at the temperature of $110^{\circ} \mathrm{C}$ to obtain the precursor of the ionic gel. The ionic gel precursor was coated on the Mo electrode by dip-coating, followed by drying in the ambient air for 1 day. A pair of Mo electrode and a cellulose as a separator were laminated to yield the Moseparator-Mo configuration using the precursor as glue. 
$X R D$ and Laser Raman spectroscopy measurement. The carbon paste was annealed at $110^{\circ} \mathrm{C}$ for 1 hour before measurement to expel the moisture inside. For the XRD (Bruker, D8 ADVANCE) measurement, the carbon and carbon paste were coated on a glass substrate by the doctor blade method using a mold with the thickness of $50 \mu \mathrm{m}$. As of the Raman spectroscopy, we used a Raman spectrometer (JASCO Corporation, NRS-5100) with a laser of $532 \mathrm{~nm}$, and carbon and the carbon paste were placed on stainless steel to reduce noise from a substrate.

Electrochemical measurement and LED illumination. The measurements were performed in the chamber filled with 1-atm of nitrogen. The CV, GCD, and EIS were conducted with a potentiostat and galvanostat (Autolab, PGSTAT204) with an EIS module (Autolab, FRA32M). We used commercially available three LEDs and a resistor of $1 \mathrm{k} \Omega$ for the LED illumination.

Dissolution of BDSC. The BDSC was immersed into the PBS (0.01 M, pH 7.4, FUJIFILM Wako Pure Chemical Corporation, lot number: SKG7696) of $100 \mathrm{~mL}$. The solution and BDSC were kept in an oven at $100^{\circ} \mathrm{C}$ to accelerate the dissolution. The solution was refreshed every two days. 
a

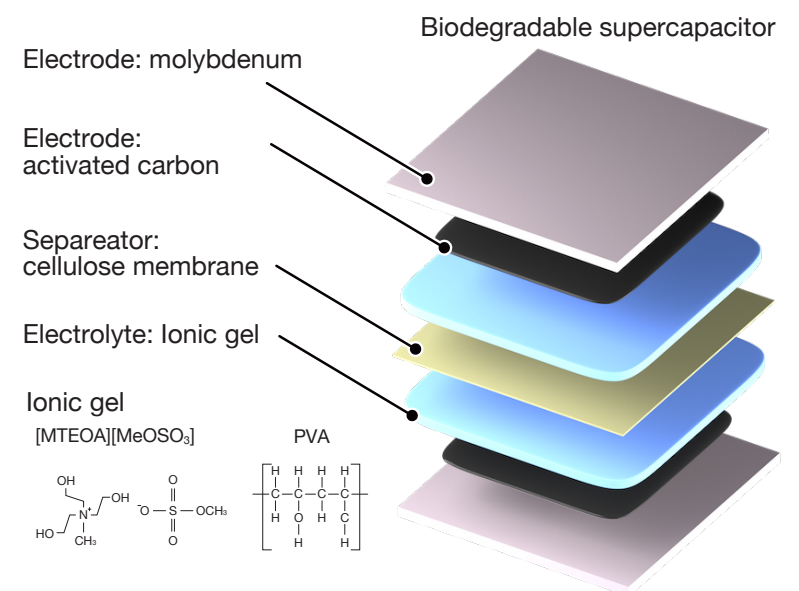

c

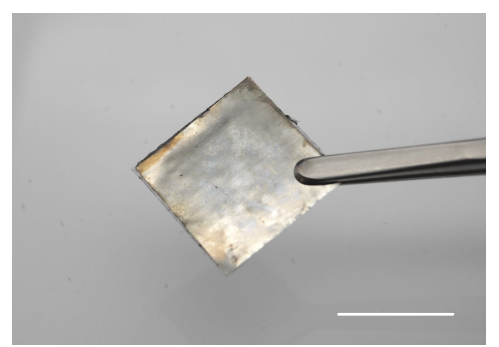

d b
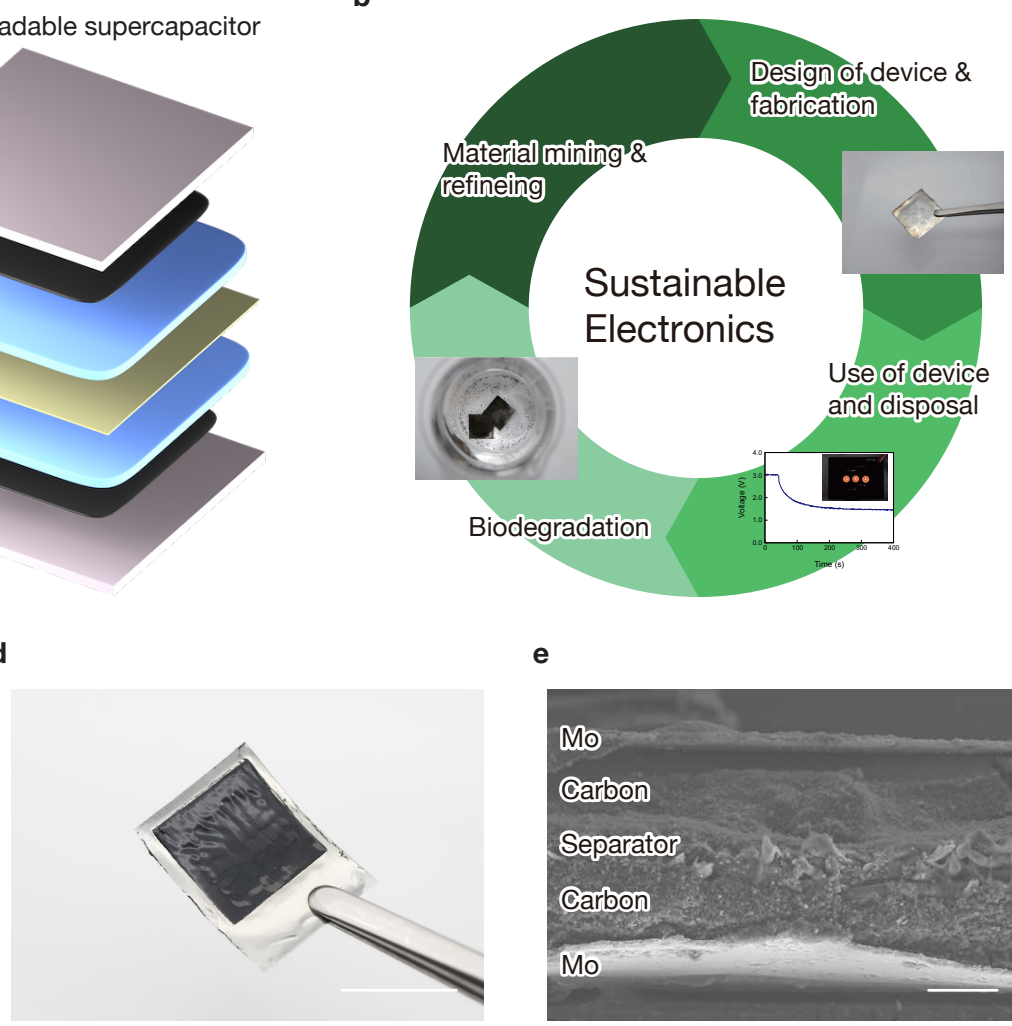

e

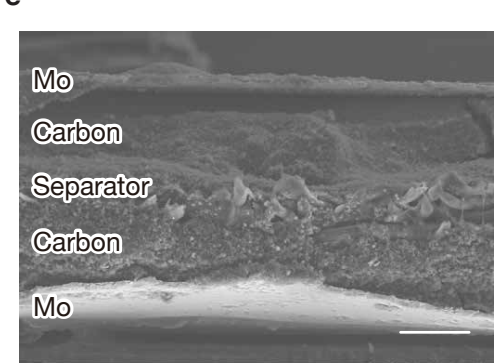

Figure 1. Schematic illustration and photographs of the biodegradable supercapacitor. (a) Schematic of the biodegradable supercapacitor and chemical formula of the ionicl liquid ([METOA] $\left.\left[\mathrm{MeOSO}_{3}\right]\right)$. (b) Illustration of sustainable electronics proposed in this paper. Photographs of (c) the developed biodegradable supercapacitor (Scale bar $10 \mathrm{~mm}$ ), (d)carbon and ionic liquid composite on the Mo electrode (Scale bar $10 \mathrm{~mm}$ ), and (e) intersection of the supercapacitor (Scale bar $50 \mu \mathrm{m}$ ). 
a

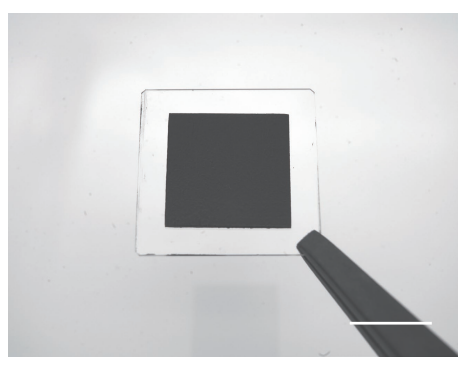

b

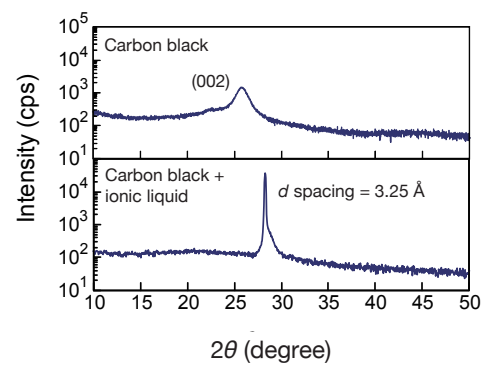

c

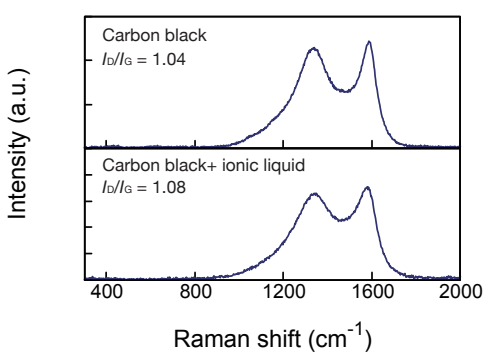

Figure 2. XRD measurement and laser Raman spectroscopy. (a) Photograph of the composite of carbon and ionic liquid. Scale bar $10 \mathrm{~mm}$. (b) XRD patterns and (c) Raman shift of the carbon black and the composite of carbon and ionic liquid. 
a
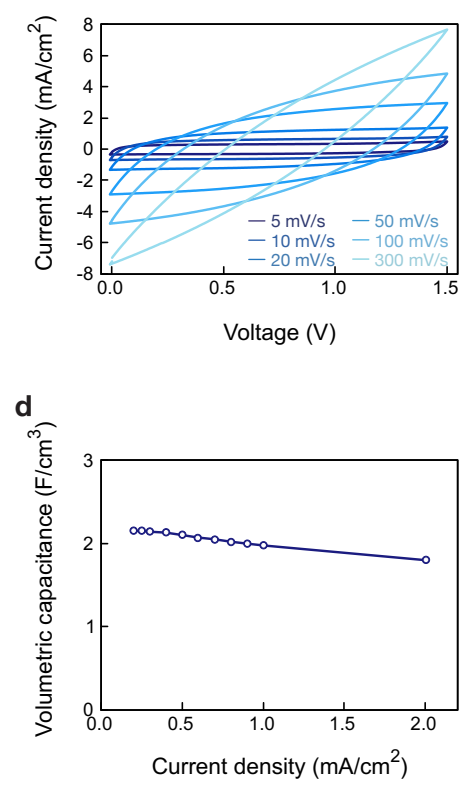

g

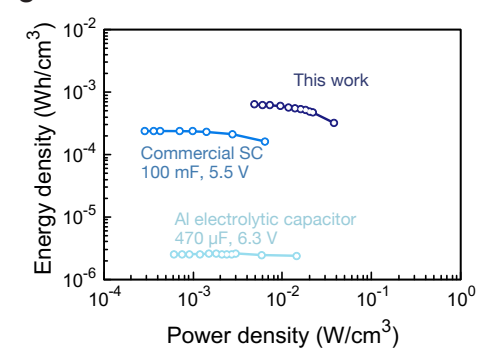

b

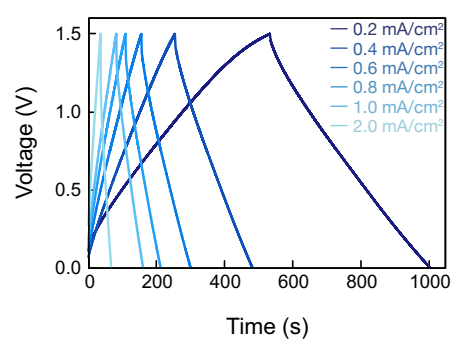

e

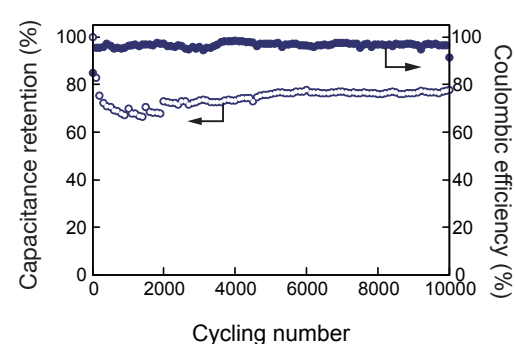

h

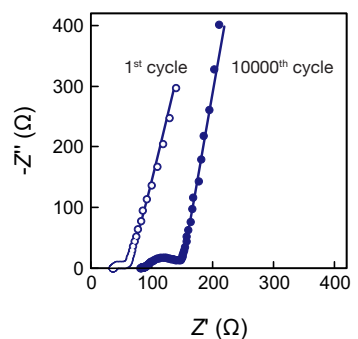

c

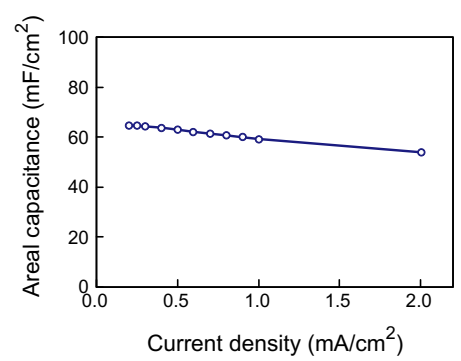

f

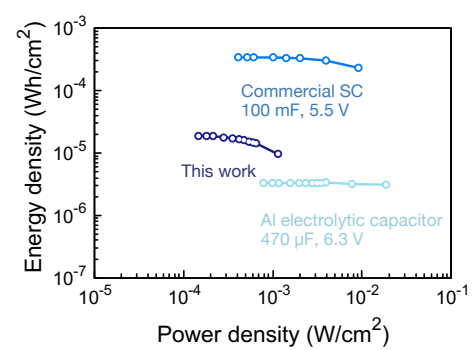

i

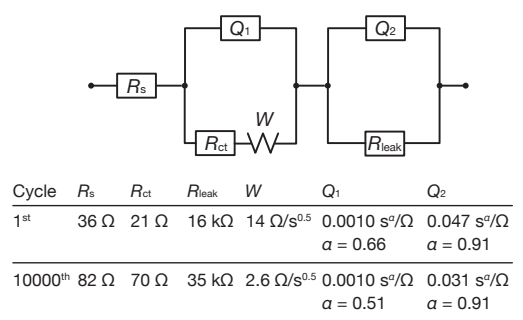

Figure 3. Electrochemical measurement on the supercapacitor. (a) CV profile with the scan rate ranging from $5 \mathrm{mV} / \mathrm{s}$ to $300 \mathrm{mV} / \mathrm{s}$. (b) GCD curves with various current densities from $0.2 \mathrm{~mA} / \mathrm{cm}^{2}$ to $2.0 \mathrm{~mA} / \mathrm{cm}^{2}$. (c) The areal and (d)volumetric capacitance calculated by the discharge current of GCD. (e) The change of the capacitance retention and coulombic efficiency during cycle test. (f) The areal and (g) volumetric Ragone plots to compare the supercapacitor in this work with a commercial supercapacitor and an Al electrolytic capacitor. (h) The equivalent circuit model obtained by fitting the Nyquist plot. (i) The Nyquist plot of the supercapacitor with the various frequency from $10 \mathrm{mHz}$ to $1 \mathrm{MHz}$ after the $1^{\text {st }}$ cycle and $10000^{\text {th }}$ cycle. 
a

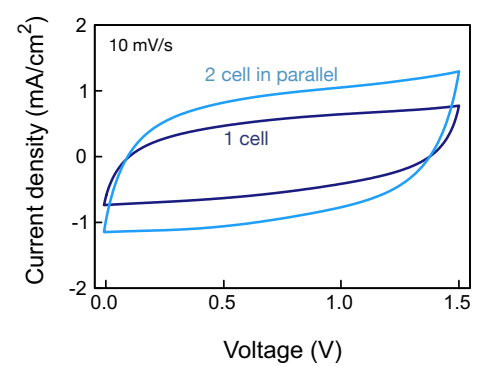

d

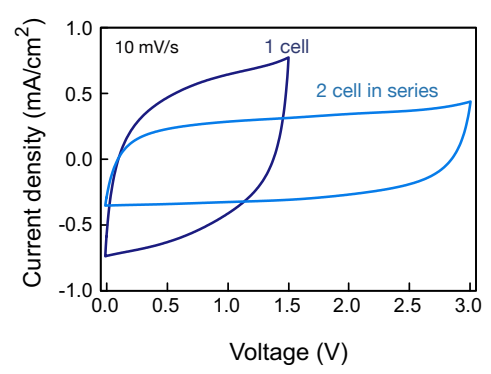

g

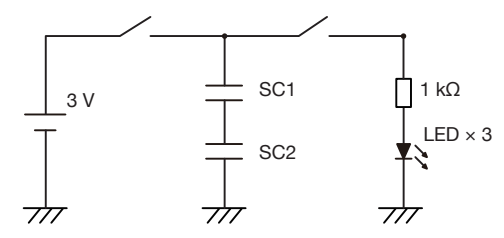

b

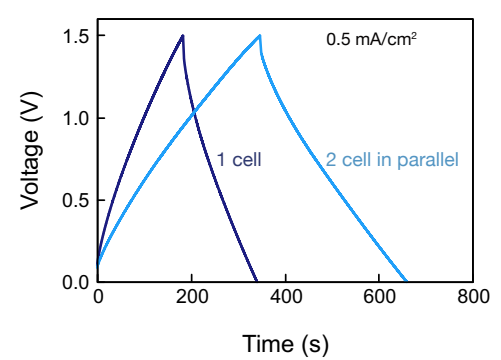

e

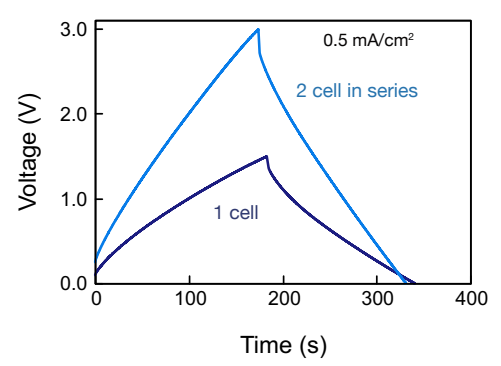

h

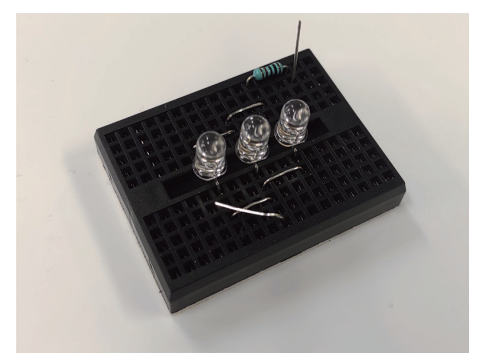

C

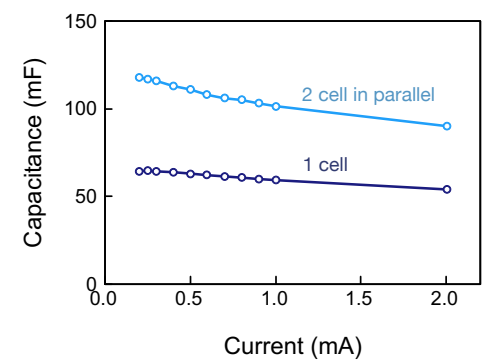

f
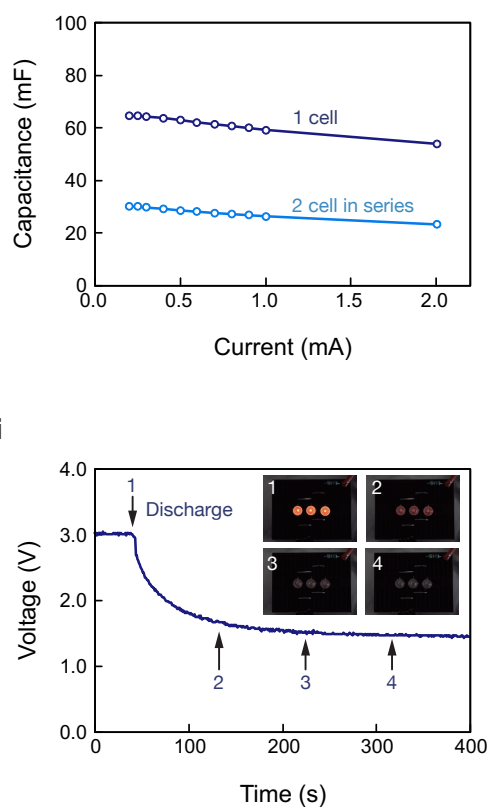

Figure 4. Electrochemical measurement on multiple supercapacitors connected in parallel and series. (a) The CV profile of one cell and two cells in parallel with the scan rate of $10 \mathrm{mV} / \mathrm{s}$. (b) The GCD curves of one cell and two cells in parallel with the current density of $0.5 \mathrm{~mA} / \mathrm{cm}^{2}$. (c) The capacitance of one cell and two cells in parallel with various current densities from 0.2 $\mathrm{mA} / \mathrm{cm}^{2}$ to $2.0 \mathrm{~mA} / \mathrm{cm}^{2}$. (d) $\mathrm{CV}$ profile of one cell and two cells in series with the scan rate of 10 $\mathrm{mV} / \mathrm{s}$. (e) GCD curves of one cell and two cells in series with the current density of $0.5 \mathrm{~mA} / \mathrm{cm}^{2}$. (f) The capacitance of one cell and two cells in series with various current densities from 0.2 $\mathrm{mA} / \mathrm{cm}^{2}$ to $2.0 \mathrm{~mA} / \mathrm{cm}^{2}$. (g) The electrical circuit to illuminate three LEDs. (h) The photograph of 
electrical circuit. (i) The transient behavior of voltage at the two supercapacitors connected in series during discharge. Photographs show the LEDs every $100 \mathrm{~s}$.
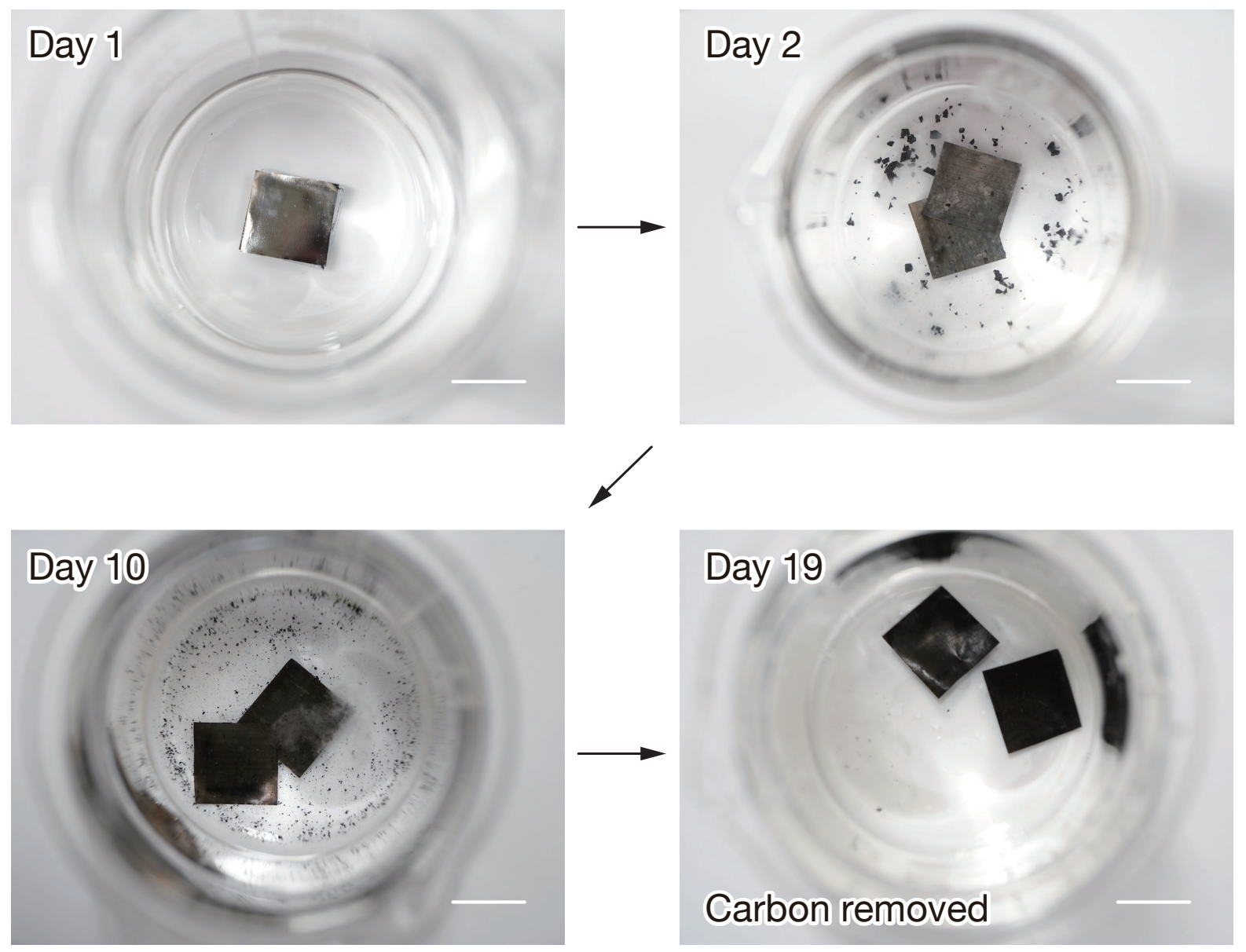

Figure 5. Photographs of transient behavior during dissolution into water. The dissolution of the PVA in the ionic gel leads to peel off the Mo electrode and break carbon composite into small fragments in day two. The Mo electrode showed glossy gray color in day one, and gradually shifted to dark gray associated with the oxidation. Scale bar $10 \mathrm{~mm}$. 


\section{AUTHOR INFORMATION}

Author's website http://santayamada.wp.xdomain.jp/

\section{ACKNOWLEDGMENT}

This work was supported in part by JSPS Grant-in-Aid for Research Activity start-up 19K23523, Japan, the Uehara Memorial Foundation, and the TonenGeneral Sekiyu Foundation.

\section{REFERENCES}

1. Lee, G.; Kang, S.-K.; Won, S. M.; Gutruf, P.; Jeong, Y. R.; Koo, J.; Lee, S.-S.; Rogers, J. A.; Ha, J. S., Fully Biodegradable Microsupercapacitor for Power Storage in Transient Electronics. Advanced Energy Materials 2017, 7 (18).

2. Esquivel, J. P.; Alday, P.; Ibrahim, O. A.; Fernández, B.; Kjeang, E.; Sabaté, N., A MetalFree and Biotically Degradable Battery for Portable Single-Use Applications. Advanced Energy Materials 2017, 7 (18).

3. Yin, L.; Huang, X.; Xu, H.; Zhang, Y.; Lam, J.; Cheng, J.; Rogers, J. A., Materials, designs, and operational characteristics for fully biodegradable primary batteries. Adv Mater 2014, 26 (23), 3879-84.

4. Fu, K. K.; Wang, Z.; Yan, C.; Liu, Z.; Yao, Y.; Dai, J.; Hitz, E.; Wang, Y.; Luo, W.; Chen, Y.; Kim, M.; Hu, L., All-Component Transient Lithium-Ion Batteries. Advanced Energy Materials 2016, 6 (10). 
5. Tian, W.; Li, Y.; Zhou, J.; Wang, T.; Zhang, R.; Cao, J.; Luo, M.; Li, N.; Zhang, N.; Gong, H.; Zhang, J.; Xie, L.; Kong, B., Implantable and Biodegradable Micro-Supercapacitor Based on a Superassembled Three-Dimensional Network Zn@PPy Hybrid Electrode. ACS Appl Mater Interfaces 2021, 13 (7), 8285-8293.

6. Lahiri, A.; Yang, L.; Höfft, O.; Endres, F., Biodegradable Zn-ion battery with a lignin composite electrode and bio-ionic liquid based electrolyte: possible in situ energy generation by lignin electrocatalysis. Materials Advances 2021, 2 (8), 2676-2683.

7. Hwang, S. W.; Tao, H.; Kim, D. H.; Cheng, H. Y.; Song, J. K.; Rill, E.; Brenckle, M. A.; Panilaitis, B.; Won, S. M.; Kim, Y.S.; Song, Y. M.; Yu, K. J.; Ameen, A.; Li, R.; Su, Y. W.; Yang, M. M.; Kaplan, D. L.; Zakin, M. R.; Slepian, M. J.; Huang, Y. G.; Omenetto, F. G.; Rogers, J. A., A Physically Transient Form of Silicon Electronics. Science 2012, 337 (6102), 1640-1644.

8. Kang, S. K.; Murphy, R. K.; Hwang, S. W.; Lee, S. M.; Harburg, D. V.; Krueger, N. A.; Shin, J.; Gamble, P.; Cheng, H.; Yu, S.; Liu, Z.; McCall, J. G.; Stephen, M.; Ying, H.; Kim, J.; Park, G.; Webb, R. C.; Lee, C. H.; Chung, S.; Wie, D. S.; Gujar, A. D.; Vemulapalli, B.; Kim, A. H.; Lee, K. M.; Cheng, J.; Huang, Y.; Lee, S. H.; Braun, P. V.; Ray, W. Z.; Rogers, J. A., Bioresorbable silicon electronic sensors for the brain. Nature 2016, $530(7588), 71-6$.

9. Lee, J. W.; Xu, R.; Lee, S.; Jang, K. I.; Yang, Y.; Banks, A.; Yu, K. J.; Kim, J.; Xu, S.; Ma, S.; Jang, S. W.; Won, P.; Li, Y.; Kim, B. H.; Choe, J. Y.; Huh, S.; Kwon, Y. H.; Huang, Y.; Paik, U.; Rogers, J. A., Soft, thin skin-mounted power management systems and their use in wireless thermography. Proc Natl Acad Sci U S A 2016, 113 (22), 6131-6. 
10. Yamada, S.; Toshiyoshi, H., A Water Dissolvable Electrolyte with an Ionic Liquid for EcoFriendly Electronics. Small 2018, 14 (32), e1800937.

11. Yamada, S.; Toshiyoshi, H., Temperature Sensor with a Water-Dissolvable Ionic Gel for Ionic Skin. ACS Appl Mater Interfaces 2020, 12 (32), 36449-36457.

12. Yamada, S.; Sato, T.; Toshiyoshi, H., A pressure sensitive ionic gel FET for tactile sensing. Applied Physics Letters 2017, 110 (25).

13. Yin, L.; Cheng, H. Y.; Mao, S. M.; Haasch, R.; Liu, Y. H.; Xie, X.; Hwang, S. W.; Jain, H.; Kang, S. K.; Su, Y. W.; Li, R.; Huang, Y. G.; Rogers, J. A., Dissolvable Metals for Transient Electronics. Advanced Functional Materials 2014, 24 (5), 645-658.

14. Shao, Q.; Tang, J.; Lin, Y.; Li, J.; Qin, F.; Zhang, K.; Yuan, J.; Qin, L.-C., Ionic liquid modified graphene for supercapacitors with high rate capability. Electrochimica Acta 2015, $176,1441-1446$.

15. Yin, C.; Liu, X.; Wei, J.; Tan, R.; Zhou, J.; Ouyang, M.; Wang, H.; Cooper, S. J.; Wu, B.; George, C.; Wang, Q., “All-in-Gel” design for supercapacitors towards solid-state energy devices with thermal and mechanical compliance. Journal of Materials Chemistry A 2019, 7 (15), 8826-8831.

16. Zheng, S.; Zhang, C.; Zhou, F.; Dong, Y.; Shi, X.; Nicolosi, V.; Wu, Z.-S.; Bao, X., Ionic liquid pre-intercalated MXene films for ionogel-based flexible micro-supercapacitors with high volumetric energy density. Journal of Materials Chemistry A 2019, 7 (16), 94789485. 
17. Fukushima, T.; Kosaka, A.; Ishimura, Y.; Yamamoto, T.; Takigawa, T.; Ishii, N.; Aida, T., Molecular ordering of organic molten salts triggered by single-walled carbon nanotubes. Science 2003, 300 (5628), 2072-2074.

18. Sekitani, T.; Nakajima, H.; Maeda,H.; Fukushima, T.; Aida, T.; Hata, K.; Someya, T., Stretchable active-matrix organic light-emitting diode display using printable elastic conductors. Nat Mater 2009, 8 (6), 494-9.

19. Yoo, S. J.; Li, L. J.; Zeng, C. C.; Little, R. D., Polymeric ionic liquid and carbon black composite as a reusable supporting electrolyte: modification of the electrode surface. Angew Chem Int Ed Engl 2015, 54 (12), 3744-7.

20. Singh, M. K.; Kumar, Y.; Hashmi, S. A., 'Bucky gel' of multiwalled carbon nanotubes as electrodes for high performance, flexible electric double layer capacitors. Nanotechnology 2013, 24 (46), 465704.

21. Ostyn, N. R.; Steele, J. A.; De Prins, M.; Sree, S. P.; Chandran, C. V.; Wangermez, W.; Vanbutsele, G.; Seo, J. W.; Roeffaers, M. B. J.; Breynaert, E.; Martens, J. A., Lowtemperature activation of carbon black by selective photocatalytic oxidation. Nanoscale Advances 2019, 1 (8), 2873-2880.

22. Liu, N.; Luo, F.; Wu, H.; Liu, Y.; Zhang, C.; Chen, J., One-Step Ionic-Liquid-Assisted Electrochemical Synthesis of Ionic-Liquid-Functionalized Graphene Sheets Directly from Graphite. Advanced Functional Materials 2008, 18 (10), 1518-1525.

23. Pan, C. J.; Yuan, C.; Zhu, G.; Zhang, Q.; Huang, C. J.; Lin, M. C.; Angell, M.; Hwang, B. J.; Kaghazchi, P.; Dai, H., An operando X-ray diffraction study of chloroaluminate anion- 
graphite intercalation in aluminum batteries. Proc Natl Acad Sci U S A 2018, 115 (22), 56705675 .

24. Qiu, T.; Yang, J.-G.; Bai, X.-J.; Wang, Y.-L., The preparation of synthetic graphite materials with hierarchical pores from lignite by one-step impregnation and their characterization as dye absorbents. RSC Advances 2019, 9 (22), 12737-12746.

25. Rajan, A. S.; Sampath, S.; Shukla, A. K., An in situ carbon-grafted alkaline iron electrode for iron-based accumulators. Energy \& Environmental Science 2014, 7 (3).

26. Simotwo, S. K.; Chinnam, P. R.; Wunder, S. L.; Kalra, V., Highly Durable, Self-Standing Solid-State Supercapacitor Based on an Ionic Liquid-Rich Ionogel and Porous Carbon Nanofiber Electrodes. ACS Appl Mater Interfaces 2017, 9 (39), 33749-33757.

27. Jin, M.; Zhang, Y.; Yan, C.; Fu, Y.; Guo, Y.; Ma, X., High-Performance Ionic LiquidBased Gel Polymer Electrolyte Incorporating Anion-Trapping Boron Sites for All-Solid-State Supercapacitor Application. ACS Appl Mater Interfaces 2018, 10 (46), 39570-39580.

28. Ujjain, S. K.; Sahu, V.; Sharma, R. K.; Singh, G., High performance, All solid state, flexible Supercapacitor based on Ionic liquid functionalized Graphene. Electrochimica Acta 2015, 157, 245-251.

29. Yang, X.; Zhang, F.; Zhang, L.; Zhang, T.; Huang, Y.; Chen, Y., A High-Performance Graphene Oxide-Doped Ion Gel as Gel Polymer Electrolyte for All-Solid-State Supercapacitor Applications. Advanced Functional Materials 2013, 23 (26), 3353-3360. 
30. Pandey, G. P.; Hashmi, S. A., Performance of solid-state supercapacitors with ionic liquid 1-ethyl-3-methylimidazolium tris(pentafluoroethyl) trifluorophosphate based gel polymer electrolyte and modified MWCNT electrodes. Electrochimica Acta 2013, 105, 333-341.

31. Wang, W.; Guo, S. R.; Lee, I.; Ahmed, K.; Zhong, J. B.; Favors, Z.; Zaera, F.; Ozkan, M.; Ozkan, C. S., Hydrous Ruthenium Oxide Nanoparticles Anchored to Graphene and Carbon Nanotube Hybrid Foam for Supercapacitors. Sci Rep-Uk 2014, 4.

32. Pean, C.; Merlet, C.; Rotenberg, B.; Madden,P. A.; Taberna,P.L.; Daffos, B.; Salanne, M.; Simon, P., On the Dynamics of Charging in Nanoporous Carbon-Based Supercapacitors. Acs Nano 2014, 8 (2), 1576-1583.

33. Hastak, R. S.; Sivaraman, P.; Potphode, D. D.; Shashidhara, K.; Samui, A. B., All solid supercapacitor based on activated carbon and poly [2,5-benzimidazole] for high temperature application. Electrochimica Acta 2012, 59, 296-303.

34. Simotwo, S. K.; Chinnam, P. R.; Wunder, S. L.; Kalra, V., Highly Durable, Self-Standing Solid-State Supercapacitor Based on an Ionic Liquid-Rich lonogel and Porous Carbon Nanofiber Electrodes. Acs Appl Mater Inter 2017, 9 (39), 33749-33757.

35. Taberna, P. L.; Simon, P.; Fauvarque, J. F., Electrochemical characteristics and impedance spectroscopy studies of carbon-carbon supercapacitors. Journal of the Electrochemical Society 2003, 150 (3), A292-A300.

36. Mukai, K.; Asaka, K.; Sugino, T.; Kiyohara, K.; Takeuchi, I.; Terasawa, N.; Futaba, D. N.; Hata, K.; Fukushima, T.; Aida, T., Highly Conductive Sheets from Millimeter-Long Single-Walled Carbon Nanotubes and Ionic Liquids: Application to Fast-Moving, Low- 
Voltage Electromechanical Actuators Operable in Air. Advanced Materials 2009, 21 (16), 1582-1585.

37. Fukushima, T.; Asaka, K.; Kosaka, A.; Aida, T., Fully plastic actuator through layer-bylayer casting with ionic-liquid-based bucky gel. Angew Chem Int Ed Engl 2005, 44 (16), 24103.

38. Wu, G.; Hu, Y.; Liu, Y.; Zhao, J.; Chen, X.; Whoehling, V.; Plesse, C.; Nguyen, G. T.; Vidal, F.; Chen, W., Graphitic carbon nitride nanosheet electrode-based high-performance ionic actuator. Nat Commun 2015, 6, 7258.

39. Zhao, D. W.; Chen, C. J.; Zhang, Q.; Chen, W. S.; Liu, S. X.; Wang, Q. W.; Liu, Y. X.; Li, J.; Yu, H. P., High Performance, Flexible, Solid-State Supercapacitors Based on a Renewable and Biodegradable Mesoporous Cellulose Membrane. Advanced Energy Materials 2017, 7 (18). 